\title{
Correlation between levels of DNA antibodies and clinical disease activity in SLE
}

\author{
Retrospective evaluation
}

\author{
P. DAVIS, J. S. PERCY, AND A. S. RUSSELL
}

From the Rheumatic Disease Unit, Department of Medicine, University of Alberta, Edmonton, Alberta, Canada

SUMMARY Sera were tested from 23 patients with systemic lupus erythematosus followed over a period of 1 to 5 years. Antibodies to native DNA were measured and correlated retrospectively with clinical evidence of disease activity. The overall degree of correlation between the presence of DNA antibodies and evidence of disease activity was good $(P<0.001)$. Of 206 sera tested, only 4 had a normal DNA antibody at a time when significant clinical activity was noted. In contrast, 34 sera had mild to moderately raised DNA antibody levels at times of clinical remission. Although DNA antibodies are a useful investigation in the monitoring of disease activity, changes in therapy should not necessarily be made on DNA antibody levels alone.

Systemic lupus erythematosus (SLE), although a relatively uncommon disease, provides one of the best examples of an immune complex disease in man. An antigen of major importance in SLE is doublestranded native DNA (n-DNA), and the ability to measure antibody to n-DNA by various techniques has proved particularly useful in diagnosing and monitoring disease activity (Koffler et al., 1971; Koffler, 1974). This paper presents our evaluation of DNA antibody measurements in monitoring disease activity in 23 cases of SLE followed-up over a period of $1-5$ years.

\section{Materials and methods}

206 sera from 23 cases who satisfy the ARA criteria for the classification of SLE were studied. All cases have been studied serially over at least one year. Serum samples were not taken more frequently than at 2-weekly intervals.

Antibodies to n-DNA were measured using a millipore filter technique (Ginsberg and Keiser, 1973) and ${ }^{3} \mathrm{H}$ labelled n-DNA extracted from a human amnion cell line (HAE 70) (Russell and Percy, 1974). Normal levels in our laboratory are $0-10 \%(<3.7 \mu \mathrm{g}$ DNA bound/ml serum). This

Accepted for publication July 8, 1976

Correspondence to Dr. P. Davis, Department of Medicine, 9-112 Clinical Sciences Building, University of Alberta, Edmonton, Alberta, Canada method using a uniform DNA gives reproducible results: $2 \mathrm{SD}=4.9 \%$. Internal control is obtained by including three standard reference sera. The purity of the extracted DNA was checked using the following parameters. (1) Reduction in fluorescence with ethidium bromide at increased $\mathrm{pH}$ showed less than a $5 \%$ contamination with single-stranded chains or breaks (Morgan and Pulleybank, 1974). (2) Test DNA did not react with a rabbit antibody to single-stranded DNA. (3) Rate of incorporation of $\mathrm{H}^{14} \mathrm{CHO}$ was within the expected range for n-DNA (McGhee and von Hippel, 1975). (4) Single-stranded DNA was removed from the double-stranded DNA by millipore filter due to the affinity of singlestranded DNA for nitrocellulose (Riggs et al., 1970).

Clinical evidence of disease activity was assessed by the presence of the following clinical signs or laboratory tests: active dermal manifestations, mouth ulcers, active hair loss, synovitis, pleurisy, pericarditis, urinary cellular casts, rising or persistently raised $(>3.5 \mathrm{~g} / 24 \mathrm{~h})$ proteinuria, mental deterioration or recent neurological signs, myositis, thrombocytopenia, or persistent unexplained fever. Emphasis was placed on the presence of an actively changing clinical status rather than simply on evidence of previous but clinically quiescent disease. Because objective assessment is so difficult, no more precise attempt at quantitation was used. Evidence of clinical activity was noted without prior knowledge of the DNA antibody levels. 


\section{Results}

The correlation between serum DNA binding levels and the clinical activity at the time is shown in the Table. There is a significant correlation between the presence of abnormal levels of DNA antibody and evidence of clinical disease activity $\left(x^{2}=81.36\right.$; $\mathrm{P}<0.001$ ). In addition, there is a general trend for the amount of DNA binding to correlate with the degree of disease activity as assessed by the number of positive clinical criteria. 118 sera had normal DNA binding and no evidence of disease activity, whereas 50 sera had high DNA binding at a time when there was some clinical evidence of activity. In only 4 sera were DNA antibodies normal at a time when some degree of clinical activity was present. In 34 sera DNA antibodies were found in varying abnormal quantities at a time when there was no clinical evidence of disease activity, i.e. a serologically active, clinically quiescent disease state. In only 11 of these instances did the high DNA binding reflect evidence of recently remitted disease activity or was it associated with impending evidence of clinical relapse. In the other 23 instances (usually those cases where DNA binding was in the intermediate $10-20 \%$ range) serological evidence of activity was not associated with any evidence of clinical activity. These midly abnormal levels usually fell spontaneously to normal on subsequent testing.

Table Numbers of sera showing correlation between clinical evidence of disease activity and corresponding levels of DNA binding

\begin{tabular}{lrrrrrrr}
\hline \multicolumn{7}{c}{ No. of clinical criteria } \\
\cline { 2 - 8 } DNA binding (\%) & \multicolumn{1}{c}{0} & $I$ & $I I$ & $I I I$ & $I V$ & $V$ & $V I$ \\
\hline $0-10$ & 118 & 3 & 1 & - & - & - & - \\
$10-20$ & 23 & 6 & 1 & - & - & - & - \\
$20-40$ & 9 & 5 & 10 & - & - & - & - \\
$40-60$ & 1 & 1 & 1 & - & 1 & 1 & 2 \\
$60-80$ & - & - & 1 & - & - & - & 2 \\
$>80$ & 1 & 3 & - & 5 & 2 & 5 & 4 \\
\hline
\end{tabular}

\section{Discussion}

The relative importance of using antibodies to double-stranded DNA as a diagnostic test has been suggested by many studies since they were first detected in SLE sera in 1958. More recently, several reports have challenged the specificity of these antibodies since they have been found in significant numbers of patients with discoid LE (Davis and Hughes, 1974), active chronic hepatitis (Davis and Read, 1975), and both rheumatoid arthritis and juvenile rheumatoid arthritis (Bell et al., 1975). Serial quantitation of these antibodies has been suggested as a valuable guide to the assessment clinical disease activity. Lightfoot in particular hạ shown that these antibodies fluctuate with disease activity and that high levels of DNA antibody clinically quiescent patients may herald disease relapse, although this relapse can occur after considerable delay (Lightfoot et al., 1975). Th correlation is not absolute and persistent serological activity may occur in the presence of persistent disease remission. The overall correlation between the presence of abnormally high DNA antibodies and clinical disease activity in our study is encouras ing, although our results emphasize the problems using only one test to assess disease activity. Whide only four sera had normal DNA antibodies at tim\& of clinical activity, it is important to note that the converse was true in 34 . Only in 11 instances did these sera represent recent remission or impendirg relapse of disease activity. Although many of these sera had DNA binding in an intermediate range $(10-20 \%$ binding $\simeq 3 \cdot 7-7 \cdot 4 \mu \mathrm{g}$ DNA bound/r serum) we believe these results represent trif serological disease activity.

Recent workshops on DNA antibodies in Los Angeles (UCLA Symposium, 1975), and Amsterdam (Feltkamp, 1975) have highlighted the problem of the quality of DNA used in various assay system. The DNA used in our millipore filter assay however, well characterized with a molecular weight (MW) of $10^{5}$. Recent work presented by Aarden an colleagues suggest that the MW of DNA used as the antigen may be important in evaluating $\mathrm{DN}$ antibodies (Aarden et al., 1975). In particular, higher binding in radioimmunoassays may be seen with high MW DNA $\left(10^{7}\right)$ when compared with lowert MW DNA $\left(10^{5}\right)$. The DNA used in our system known to be free of significant quantities of singlestranded DNA ends or breaks as assessed by the techniques previously described. One explanation for the lack of correlation between DNA antibody in 34 sera levels and disease activity may be the lack sensitivity of the criteria used to assess clinical activit: Edmonds and Hughes (1974) have reported that a significant number of patients who were previously thought to be in remission did have evidence of disease activity with more extensive clinical investige्a tion.

Our results suggest that although useful, DN antibodies alone should not be the only criterion by which disease activity in SLE is assessed but that other parameters such as serum complement levets and evidence of circulating immune complexes mag produce useful supplementary information (Dav et al., 1977). Evaluation of levels of DNA antiboof should also be made in the light of current views on the antigen and method used. 
Our findings essentially agree with data from previous reports, but, as the emphasis of these articles has been in other areas, the relationship between DNA binding and clinical disease activity is not always clear. Serial samples in our patients have enabled us to document definite, though mild, serologically active disease in the absence of active clinical features. In addition, the high degree of characterization of the DNA used in our assay system excludes the possibility that the similar results obtained in previous studies were due to contamination of test antigen by single-stranded DNA.

\section{References}

Aarden, L. A., Lakmaker, F., Degroot, E. R., Swaak, A. J. G., and Feltkamp, T. E. W. (1975). Detection of antibodies to DNA by radioimmunoassay and immunofluorescence. Scandinavian Journal of Rheumatology, Suppl. 11, 12-19.

Bell, C., Talal, N., and Schur, P. H. (1975). Antibodies to DNA in patients with rheumatoid arthritis and juvenile rheumatoid arthritis. Arthritis and Rheumatism, 18, 535-540.

Davis, P., and Hughes, G. R. V.(1974). Anti-DNA antibodies in discoid lupus erythematosus. British Journal of Dermatology, 91, 175-181.

Davis, P., and Read, A. E. A. (1975). Antibodies to ds (native) DNA in active chronic hepatitis. Gut, 16, 413-415.

Davis, P., Cummings, R., and Verrier-Jones, J. (1977). Relationship between antibodies to N-DNA, complement consumption and circulating immune complexes in systemic lupus erythematosus. Clinical and Experimental Immunology (in press).
Edmonds, J. P., and Hughes, G. R. V. (1974). Subclinical involvement and serological abnormalities in 'minimal lupus'. (Abst.) Scandinavian Journal of Rheumatology, Suppl. 8, 42-44.

Feltkamp, T. E. W. (1975). (Editor.) The significance of the determination of anti-DNA and DNA/anti-DNA complexes. Scandinavian Journal of Rheumatology, Suppl. 11, $1-64$.

Ginsberg, B., and Keiser, H. (1973). A millipore filter assay for antibody to native-DNA in sera of patients with SLE. Arthritis and Rheumatism, 16, 199-207.

Koffler, D. (1974). Immunopathogenesis of systemic lupus erythematosus. Annual Review of Medicine, 25, 149-164.

Koffler, D., Carr, R. I., Agnello, V., Thoburn, R., and Kunkel, H. G. (1971). Antibodies to polynucleotides in human sera: antigenic specificity and relation to disease. Journal of Experimental Medicine, 134, 294-312.

Lightfoot, R. S., Redecha, P. B., and Levesanos, N. (1975). Longitudinal studies of anti DNA antibody levels in SLE. Scandinavian Journal of Rheumatology, Suppl. 11, 52-58.

McGhee, J. D., and von Hippel, P. H. (1975). Formaldehyde as a probel of DNA structure. Reaction with exocyclic amino acid groups of DNA basis. Biochemistry, 14, 1281-1296.

Morgan, A. R., and Pulleybank, D. E. (1974). Native and denatured DNA, crosslinked and palindromic DNA and circular covalently closed DNA analysed by a sensitive fluorometric procedure. Biochemical and Biophysical Research Communications, 61, 396-403.

Riggs, A. D., Suzuki, H., and Bourgeous, S. (1970). Lac repressor-operator interaction. 1. Equilibrium studies. Journal of Molecular Biology, 48, 67-83.

Russell, A. S., and Percy, J. S. (1974). The antigenicity of polynucleotides in mink, rabbit and man. Journal of Rheumatology, 1, 66-73.

UCLA Symposium (1975). Immunopathology of nucleic acid in rheumatic diseases. Journal of Rheumatology, 2, 125-224. 